\title{
Editorial
}

\section{Memorias de un confinamiento: acercamiento a las vivencias del Covid 19 en Colombia}

Esta segunda mitad del año 2020 no ha dejado a nadie en el mundo impávido, ya no solo debido a la emergencia sanitaria global a causa del Sars-CoV-19, sino gracias a que, conforme los humanos han ido rediseñando su normalidad en correspondencia a las nuevas y cambiantes medidas de higiene y distanciamiento social para prevenir la propagación del virus, a la crisis se han ido sumado paulatinamente diversos tipos de eventos y situaciones de carácter político, cultural y social que recuerdan que la Covid-19 no es el único factor por el cual se debe estar atento hoy por hoy.

Así, en estos últimos meses se ha dividido el mundo entero en dos hemisferios separados por el Océano Atlántico: por un lado Europa, Asia y parte de África — que habían venido disfrutado del aplacamiento del virus y de la denominada nueva normalidad - en la actualidad están retornando a las medidas estrictas de confinamiento y cierre comercial; mientras que América, especialmente el territorio latino, ha estado derogando progresivamente las medidas estrictas de cuarentena y el comercio se encuentra en tránsito a la reactivación.

En esa medida, este es un momento coyuntural para todo el globo: la segunda oleada de casos de Covid-19 azota fuertemente a Europa, como se vaticinó meses antes y, aunque Latinoamérica se encuentre en medio de un respiro, es lógico pensar que en un tiempo no muy lejano se presente una situación similar trasladando el foco de la enfermedad de nuevo a este lado del mundo. Es momento de prepararse y tomar el ejemplo de quienes parecen estar unos pasos en el tiempo delante de nosotros.

En Colombia los habitantes han venido retornando progresivamente a sus funciones habituales siguiendo las recomendaciones de salubridad. No obstante, si bien una gran parte de la población continúa realizando sus actividades cotidianas mediante la virtualidad, la realidad en el país no ha permitido escenarios de colaboración ciudadana como los que se han visto en Europa: las condiciones sociales y economías del grueso de la población la ha empujado a las calles en la búsqueda de los elementos básicos para subsistir.

En consecuencia, si bien se evidencia un avance en relación con la pandemia, Colombia ha estado inmersa en diversas situaciones que recuerdan la realidad nacional: para el mes de julio las masacres no han dejado de aumentar y los enfrentamientos entre las Fuerzas Armadas de la nación y diversos grupos armados ilegales parecen ir en aumento sin importar en nada el confinamiento o la pandemia misma. Tal fue el panorama para el día 6 de julio, donde un total de 94 congresistas de los Estados Unidos firmaron un comunicado, a través de Mike Pompeo, para solicitar a Iván Duque el cumplimiento de los acuerdos de paz firmados con las extintas Fuerzas Armadas Revolucionarias de Colombia-Ejército del Pueblo (FARC-EP) en 2016, y proteger la vida de los líderes sociales que hasta esa fecha superaban la cifra de 400 asesinatos en lo corrido del año.

Por otro lado, el 2020 se ha tornado agridulce para las instituciones que componen la Fuerza Pública. Se conoce un total de 118 investigaciones a miembros del Ejército Nacional por delitos sexuales, entre ellos diversos casos que involucran ataques en contra de menores de edad; asimismo, estallan diferentes polémicas nacionales en torno al uso desmedido de la fuerza por parte de la Policía Nacional, siendo la más mencionada en los medios de comunicación del país, tal vez porque se viralizó en redes sociales a través de un video incluso antes de aparecer en los noticieros, la muerte de Javier Ordóñez, un abogado que fue reducido en repetidas ocasiones con un taser por efectivos de la Institución y quien resultó muerto en un hospital en Bogotá con signos de una fuerte golpiza.

Todos estos hechos han acompañado una de las convulsiones más sonadas a nivel político de los últimos años o incluso décadas en el país. En los primeros días del mes de agosto la Corte Suprema de Justicia, entidad que adelantaba una investigación contra el Expresidente y en ese momento Senador de la República Álvaro Uribe Vélez por delitos de soborno y fraude procesal, ordenó su detención domiciliaria convirtiéndolo en el primer exmandatario del país privado de la libertad.

La respuesta por parte del movimiento uribista a la decisión de la Corte no se hizo esperar y para el día 5 de agosto se realizaron diversas caravanas de vehículos por las principales avenidas del país en exigencia de su libertad, mientras en las plazas públicas se manifestaba el otro sector de la población en apoyo del proceso judicial. Casi dos semanas después Mike Pence, vicepresidente de los Estados Unidos, llamó héroe a Álvaro Uribe y solicitó su libertad. Con todo, 
el día 18 de agosto Uribe renunció a su curul en el Senado de la República y de nuevo las opiniones del grueso de la población se polarizaron en el apoyo al exmandatario y en odas al proceso llevado a cabo por la Corte Suprema de Justicia.

En medio de esta convulsión política, la violencia continuó avanzando sin tapujos a los diversos territorios del país. Masacres como la de Puerto Santander (Norte de Santander), que dejó un saldo de seis muertos, y la de Samaniego (Nariño) que dejó un total de nueve jóvenes asesinados, han llevado a varios de los medios de comunicación internacionales a sentenciar que la violencia en Colombia se está recrudeciendo y está camino a alcanzar los niveles vistos en décadas anteriores; desde entonces hasta finales del mes de septiembre se vino registrando una masacre en el país casi que un día de por medio.

En consecuencia, los ánimos de los colombianos siguieron en aumento y para el periodo que comprende del 9 al 15 de septiembre se realizaron diversas marchas y protestas en Bogotá, impulsadas por el video de la agresión policial a Javier Ordoñez. Esta fue una serie de manifestaciones que enmarcaron la quema de 39 Comandos de Atención Inmediata (CAI) y 25 buses del servicio de transporte público de Bogotá; ante tal situación se militarizó la ciudad, lo que inicio una serie de enfrentamientos entre los manifestantes y la fuerza pública. Esta jornada de protestas dejó un saldo oficial de 93 policías y 55 civiles lesionados. Mientras que los medios tradicionales de comunicación se refieren a los hechos como vandálicos, algunos canales de información alternativos nombraron a la jornada como La masacre de Bogotá, debido en gran parte a los diversos videos y evidencias del uso desmedido de la fuerza y de armas de fuego por parte de efectivos de la Policía Nacional.

En medio de la jornada de propuestas, el día 10 de septiembre, el director actual de la Jurisdicción Especial para la Paz (JEP), Giovanni Álvarez Santoyo, ratificó la advertencia de que el país se está acercando al umbral de violencia que se vivió en el periodo que comprende los años 1998 al 2002. Unos días después, finalizando la segunda semana del mes, las masacres parecieron detenerse por un momento, pero regresaron poco tiempo después: el 20 de septiembre siete jóvenes fueron masacrados en Buenos Aires (Cauca).

A raíz de los hechos ocurridos en Bogotá, que desbordaron los imaginarios de muchos de los dirigentes del país, incluyendo el de la alcaldesa de la capital Claudia López, quien llamó al presidente Iván Duque a trabajar por una reestructuración institucional de la Fuerza Pública, el 22 de septiembre se hace histórico el fallo de la Corte Suprema de Justicia, que tomó en consideración los hechos ocurridos referentes al uso de la fuerza por los miembros de la Policía Nacional y el Escuadrón Móvil Antidisturbios (ESMAD) en las protestas sociales desde finales del año 2019, en donde se prohíbe el uso de la escopeta calibre 12 por el ESMAD, se solicita al Ministerio de defensa pedir disculpas públicas por los abusos de la Fuerza Pública en las recientes manifestaciones y se exige desplegar un plan garante para la protesta social en el país.

Los imaginarios de la población colombiana, respecto a la política, la sociedad, la economía, la salud y la vida han venido cambiando y el año 2020 ha sido un factor importante en ello, pues dejó al descubierto un abanico tristemente complejo de problemáticas y asimetrías irresolutas que tomaron partido del momento de crisis que auspició la pandemia mundial, para expandirse por todo el territorio nacional y convulsionar aún más un panorama que de por sí siempre ha estado en constante malestar. El gobierno actual parece no haber atinado a muchos de los objetivos que prometió atender en medio de la campaña presidencial; una situación que se cristaliza en la constante caída de popularidad de Iván Duque como mandatario del país, que para finales del mes de octubre rondaba el 63\% de desfavorabilidad.

\section{¿Qué ofrece la edición 13.2 de la revista Ciudad Paz-ando?}

El proceso para la publicación de esta edición de la revista Ciudad Paz-ando se ha desarrollado y culminado en medio de un momento particular de la historia del mundo. Las crisis se han convertido en palabras que, aunque siempre fueron recurrentes, hoy son familiares para todo habitante en el globo; por ello, las meditaciones y reflexiones acerca de los posibles futuros y devenires del mundo no son pocos, mucho menos lo son los que provienen de la labor investigativa de la academia. En este escenario, el panorama de Colombia ha demostrado que a pesar de tener un enemigo invisible que amenaza con acabar con la vida de todos, los peligros de siempre no desaparecen y que, de hecho, parecen tomar ventaja del miedo generalizado de la población y con ello parecen apostar por el avance de la violencia a lugares donde esta parecía erradicada. Sin duda, es un momento coyuntural para la comunidad internacional y para el país no es distinto, ya por la pandemia actual, ya por la violencia que no logramos dejar atrás.

Iniciando el dossier central de esta edición, Martha Lucía Ortiz presenta un análisis sobre la inseguridad jurídica que acaece sobre el sistema de justicia nacional debido a los conflictos y discrepancias presentes en los procesos disciplinarios del país, específicamente sobre el debate inacabado de la vinculación de contratistas para llevar a cabo esta labor por sobre los funcionarios del Estado. Posteriormente, David Ramos, Wendy Díaz, Sharon Benítez, Laura Camila y Laura Solano, ofrecen un documento que da cuenta del proceso de creación del proyecto Cartografía de las memorias 
familiares, realizada por el semillero de investigación en Arte y Memoria Incandescencias: del recuerdo a la Creación de la Universidad Pedagógica Nacional. Una discusión en donde se presentan reflexiones acerca de los vehículos que articulan las memorias y las herencias que cimientan los procesos de transmisión generacional.

A renglón seguido, se presenta un artículo que, de la mano de Julián Andrés Montañez, pone en discusión la naturaleza e importancia del archivo como historia viva para un Estado, evidenciando que el desarrollo de las labores que se inmiscuyen en su construcción están permeadas por una constante pugna entre el derecho y el privilegio en el país. Seguidamente, Jairo Crispín reflexiona acerca del trabajo de un grupo de practicantes de la Universidad Nacional de Colombia en el Museo Nacional de Memoria, colocando sobre la mesa, desde la frónesis y el pensamiento práctico, diversas iniciativas entorno a la memoria del conflicto armado que han colaborado a la construcción de paz y cambio social constructivo en el territorio del país.

Continuando con la discusión referente a la historia y la memoria, Roger Pita escribe acerca de la Independencia de Colombia desde una perspectiva revisionista, señalando, entre otras cosas, que para el desarrollo de una ciudadanía memorial es necesaria reevaluar la historia desde un enfoque integral que enmarque de manera holística todas las relaciones de poder que se desarrollaron en los tiempos pasados. Finalizando el dossier central de este número, Lised García realiza un amplio análisis sobre el devenir de la mujer que, desde un abordaje de carácter ontológico y político, sustenta la idea de la naturalización monstruosa de la feminidad a partir de las localizaciones culturales, políticas y sociales.

Más adelante, en la sección Pensando regiones, se presenta un documento que reflexiona sobre los sentires e imaginarios de las infancias del municipio de Caucasia (Antioquia) sobre Hidroituango, en donde Adriana Arroyo habla de las percepciones de la comunidad acerca de los impactos ambientales y sociales del mega proyecto de la hidroeléctrica en la región, sugiriendo una nueva apuesta política y juvenil para el desarrollo territorial del país. Posteriormente, el apartado Voces otras expone un artículo, de la autoría de Jaime Alberto Cimadevilla, que presenta una potente reflexión sobre los contextos económicos y sociales de los años sesenta en Colombia que llevaron a la formulación de acciones cívico-militares, como una estrategia de las Fuerzas Armadas para abordar los desafíos sociales y económicos de distintas comunidades en todo el país.

Como una suerte de antesala al cierre, los editores de este número presentan la entrevista realizada a Diana Britto, quien además de ser una figura destacada a nivel nacional en temas referentes a la justicia restaurativa y la construcción de paz, actualmente se desempeña como coordinadora de la Dirección de Conocimiento de la Comisión de la Verdad de la Nación. Así, finalmente, la reseña de esta edición de Ciudad Paz-ando está dedicada al Diccionario de Memoria Colectiva que, con un total de más de 180 autores, vio la luz en el año 2018 bajo la dirección del historiador catalán Ricard Vinyes, quien a partir de su amplio conocimiento sobre la memoria social ha sido parte del equipo de trabajo de la Comisión redactora del proyecto del Instituto de la Memoria del Gobierno Vasco.

Para terminar, agradecemos profundamente a la Universidad Distrital Francisco José de Caldas y al equipo del Instituto para la Pedagogía, la Paz y el Conflicto Urbano - IPAZUD porque, a pesar de encontrarnos en un momento tan particular y complicado, siguen haciendo posible que la Revista Científica Ciudad Pazando continúe esta importante labor encaminada a difundir los trabajos de investigación que traen a la palestra temas tan importantes para la actualidad nacional como lo es la paz.

Jairo AndRés Hernández Cubides Jefferson Arley Díaz Mesa

EDITORES

Revista CiUdad Paz-ANDO 